\title{
Optimizing Resource Allocations With A Strategic Focus: An Accounting Perspective
}

Joseph M. Larkin, Saint Joseph's University, USA

\begin{abstract}
This case focuses upon the pharmaceutical industry and key financial and strategic management decisions. An international pharmaceutical firm plans to launch a new product. The organization must decide whether or not to increase their internal sales force or hire a Contract Sales Organization for the product launch. Students will have to analyze the quantitative cost information as well as consider qualitative considerations.
\end{abstract}

Keywords: Outsourcing Budgeting, Make-or-Buy Decision and Pharmaceutical Industry

\section{INTRODUCTION}

\section{Healthcare Detailers, Inc.}

alaxy Pharmaceuticals, Inc. (GPI) is an international pharmaceutical firm focusing on discovering, developing, manufacturing and marketing medicines. It is one of the largest organizations in the industry. Last year, revenues topped $\$ 12$ billion - an increase of 18 percent over the previous year. Net income for the year was $\$ 1.9$ billion and diluted earnings per share were \$2.05. Galaxy is recognized as one of the most admired companies in the world and the world's most-admired pharmaceutical company. Much of GPI's success is attributable to its increased focus on its core competencies - namely - discovering, developing and bringing to market innovative medicines to save, protect and enhance people's lives. Although GPI has its own sales force, management views sales efforts as a staff function, preferring to concentrate on research and development.

\section{Strategic Focus}

At the beginning of the past decade, GPI's portfolio of products ranged from personal products and pigments to chemicals and medical devices. Since then, they have steadily narrowed their focus on the business they know best, the business in which they have had the greatest success, and the business that offers them the most opportunities: the pharmaceutical business.

The company is in the process of a strategic repositioning from a broad-based health care company to a focused, research-based pharmaceutical company by divesting those businesses outside of the pharmaceutical business.

All of Galaxy's energies and resources are now concentrated on discovering, developing, manufacturing and marketing medicines. This focus positions GPI to expand the therapeutic breadth of their product line, to increase their global presence, and to accelerate their use of the advanced technologies that are helping to usher in a "golden age" of science.

\section{The Pharmaceutical Industry}

The pharmaceutical industry is passing through a very challenging period in its evolution with the traditional approaches to drug development and marketing constantly changing. Successful pharmaceutical organizations have recognized the need to leverage resources, and as a result, they have come to rely on the wealth of expertise provided by specialist external sources. Some companies within the industry outsource all or portions 
of the sales and marketing function to outside vendors, thereby enabling them to focus upon and further develop their core competencies.

Today's customers have more choices, and those choices move through the product approval and launch stages faster than ever. Companies need to accelerate their efforts in an increasingly competitive marketplace than now encompasses continents, not just countries. Customer focus is a key driving force in the industry. There is a strong focus on relationship-building between the organization and the customer. This phenomenon makes the selling function vitally important. Those companies that can develop and bring to market products in a fast, efficient and economical fashion will thrive. Those that cannot will not survive.

The pharmaceutical industry operates in a highly regulated environment. The Food and Drug Administration is the governmental branch responsible for the overseer function. A new product cannot be brought to market without their approval. It takes years of research to develop a new medicine. The testing and approval process involves several phases. Cumulatively, the entire process - from development through approval to product launch will typically take years. Time is of the essence for pharmaceutical companies. Patent protection is vital for a company's profitability. Once a product goes "off patent," it faces competition from generic drug makers. At that moment, market share for the original manufacturer will generally decrease dramatically.

Therefore, it is critical to "take the product to market" as soon as possible. If the manufacturer does not have an in-house sales force, or their current sales force is occupied, companies will rely on outside vendors to provide or supplement the sales function.

\section{Outsourcing}

Outsourcing is a concept whereby an organization hires outsiders to perform some function previously performed "in-house." For example, for many years some organizations have used outside services to process payrolls. Virtually, almost any function is a candidate for outsourcing. Typically, outsourcing firms take advantage of economies of scale, allowing them to performs tasks far more efficiently and cost effectively than if the task were performed "in-house."

Companies outsource for many reasons. One company may outsource in order to focus on core capabilities or take advantage of a particular competence of an outside company. Another may outsource for financial reasons. Although financial reasons ultimately involve reduction of costs or increased cost effectiveness, utilizing outside organizations to perform various functions allows companies to avoid building often cumbersome infrastructures. The motivating factors can vary. One company may seek to avoid increasing infrastructure, whereas another may aim to reduce the rate of sales force increases or even current staff expenditures. Speed to market and flexibility are additional reasons for a company to outsource some or all of its projects. Many companies may do so for more than one reason.

\section{Contract Sales Organizations}

The Contract Sales Organization (CSO) concept was introduced in the United States in the 1950s, but did not gain strength in the pharmaceutical industry until the mid-1980s. Regulatory and cost containment pressures led companies to seek a more efficient method of promoting new and existing programs. Contract sales organizations proved to be an economical, flexible and highly efficient means of influencing prescribing patterns among targeted physicians.

In the 1990s, the proliferation of managed care providers led companies to seek broader solutions in the United States. CSOs were a cost-effective alternative to expanding in-house forces or entering into co-marketing agreements. CSOs play varied roles within the industry. For example, they can be involved with major launch programs, calling on Managed Care Organizations (MCO), or direct calls to physicians.

Many clients of CSOs have adopted a basic policy of maintaining an undersized sales force and relying on CSOs to bring their representation up to strength. 


\section{The Role of Sales Representatives}

Pharmaceutical sales representatives interact with several categories of customers. The list includes: buyers and purchasing agents of managed care organizations (MCOs), pharmaceutical benefit management companies (PBMs), health maintenance organizations (HMOs), long-term care institutions, wholesalers, retailers, and physicians. "Detailing" is the process of presenting the drug to the prospect. Obviously, there is a great deal of critical information that must be presented. This information includes: a product's benefits, uses, side effects, adverse interactions with other medications, and adverse clinical events. Sales representatives must knowledgeable about all of these issues. Time and time again, detailing has proven to influence physician prescribing behavior. It is estimated that detailing represents approximately $65 \%$ of total pharmaceutical promotional spending.

Training and product knowledge is crucial for pharmaceutical sales representatives. They must have not only strong selling skills but also, a strong knowledge of their products. It is understandable then, that sales representatives require substantial and frequent training and educational opportunities. Usually, representatives have a very limited amount of "face time" with their prospect. Therefore, it is essential that they spend what time they have in an efficient manner.

Often times, sales representatives have a background including a degree in a life science. For example, pharmaceutical sales is a common career path for biology, chemistry or pre-medicine majors who did not pursue medical school studies.

The employment selection process for pharmaceutical sales representatives is very selective. Compared to other sales careers, the compensation package for pharmaceutical sales representatives is very attractive.

\section{Healthcare Detailers Inc.}

Healthcare Detailers, Inc. (HDI) is a leading provider of comprehensive customized sales solutions on an outsourced basis to the United States pharmaceutical industry. HDI has designed customized product detailing programs for some of the world's largest pharmaceutical companies. The company has achieved a leadership position based upon its years of industry experience and its relationships with many of the pharmaceutical industry's largest companies. HDI, founded in 1975 has over 30 years of experience in the field. They are one of the top CSO's in the country.

HDI provides product detailing programs and other marketing and promotional services to the United States pharmaceutical industry. Most of its business involves designing and executing customized product detailing programs for both prescription and over-the-counter products. The contract structures between HDI and their clients vary. Usually, the terms of product detailing contracts range from 12 to 36 months. Generally, all of the contracts provide for a fee to be paid to HDI based on their ability to deliver a specified package of services. For example, additional fees may be paid based upon the achievement of certain performance benchmarks. Also, penalties may be incurred for failing to meet the stated minimum benchmarks, such as number of sales representatives or number of sales calls.

The majority of the contracts can be terminated by the client for any reason on 30 to 90 days notice and may also be terminated for cause if stated performance benchmarks are not achieved. To date, none of HDI's programs have been terminated for cause.

\section{Revenue Streams}

Product detailing programs are the largest source of revenue. In addition, other marketing and promotional services provide revenue. Product detailing programs represent the largest and fastest growing portion of total revenue but have lower gross profit margins than other service offerings. Revenue is recognized as the services are performed and the right to receive payment for the services is assured. In the case of contracts relating to product detailing programs, revenue is recognized net of any potential penalties until the performance criteria eliminating the penalties have been achieved. 


\section{Program Expenses}

Program expenses consist primarily of the costs associated with executing a product detailing program or the other services identified in the contract. They include personnel costs and other costs such as facility rental fees, honoraria and travel expenses, associated with executing a product detailing or other marketing or promotional program, as well as the initial direct costs associated with staffing a product detailing program. Personnel costs constitute the largest portion of program expenses and include all labor related costs, such as salaries, bonuses, fringe benefits and payroll taxes for the sales representatives and sales managers and professional staff who are directly responsible for executing a particular program. Initial direct program costs are those costs associated with initiating a product-detailing program. They include recruiting, hiring and training the sales representatives who staff a particular product detailing program. All personnel costs and initial direct program costs, other than training costs, are expensed as incurred. Training costs include the costs of training the sales representatives and managers on a particular product detailing program so that they are qualified to properly perform the services specified in the related contract. Training costs are deferred and amortized on a straight-line basis over the shorter of the life of the contract to which they relate or 12 months.

\section{Request For Proposal (RFP)}

Recently, HDI was approached by Galaxy Pharmaceuticals, Inc. and invited to submit an RFP to deliver a direct, dedicated sales force to promote GPI's soon to be launched blood pressure medicine, Lobeat. Although GPI has an in-house sales force, management wishes to supplement it with an additional 450 sales representatives. The board of directors of Galaxy has authorized management to begin the selection process for an outside vendor to supply the additional sales representatives. HDI is one of several CSOs invited to propose for the account. The contract would last for one year with the option to extend it for a second year.

John Collins, HDI's vice president for development has had several meetings with GPI's management team which provided him with the contract specifications. Based upon the information in the contract, Collins has gathered the information that appears below.

\section{Service and Management Fees}

These charges cover all compensation, bonuses, taxes and benefits for all program-assigned personnel, excluding the sales representatives, plus overhead and profit margins for HDI. Total cost: $\$ 9,000,000$.

\section{Representative Employee Costs}

Four hundred fifty full-time sales representatives will be assigned.

The average annual salary per representative is estimated at $\$ 47,000$.

An annual bonus will be accrued at $20 \%$ of base salary for each representative.

Payroll taxes are estimated to be $11 \%$ of salary and bonus.

Automobile allowances are based on a monthly cost of $\$ 600$ per representative.

Healthcare benefits are estimated to cost a monthly average of $\$ 432$ per month per representative.

Workman's compensation is projected at an annual rate of $\$ 200$ per representative.

The cost to recruit each representative is estimated to amount to $\$ 5,000$. Annual representative turnover is estimated to be $10 \%$. The cost to recruit replacement representatives is the same as initial recruitment costs. 


\section{Field Manager Costs}

Forty-five field managers will be needed to supervise the sales representatives. Field manager's salaries are projected at $\$ 72,000$ per manager.

An annual bonus will be accrued at $20 \%$ of base salary for each manager.

Payroll taxes are estimated at $11 \%$ of salary and bonus.

Workman's compensation is projected at an annual rate of $\$ 200$ per manager.

Automobile allowance is projected at $\$ 700$ per month per manager.

Healthcare benefits for the field managers are estimated to be the same as those of the sales representatives.

\section{In-Territory Expenses}

Transportation expenses, in addition to automobile allowances are projected at $\$ 270$ per month, per representative and field managers. These expenses include: gasoline, parking, fares and tolls.

Business development expenses are estimated at $\$ 400$ per month per representative.

These expenses include programming, client entertaining and other, similar expenses.

All samples will be provided by GPI.

\section{Training Expenses}

Initial training is for 20 days per representative at a daily cost of $\$ 500$ per day, which includes instruction, training materials, meals, lodging and, transportation to and from the training location.

Based on the turnover rate estimated above, costs to train the replacement representatives are to be included in the calculation.

\section{Training Meetings}

Two Plan of Action meetings will be held. Estimated costs for each three-day meeting are $\$ 400$ per day per person. All sales representatives and the field managers will attend.

All sales representatives and field managers will attend the four-day national sales meeting. The cost is projected at $\$ 1200$ per day per person.

\section{Database Management}

GPI will provide each representative with a laptop computer and will provide all database management services.

\section{Program Administration}

Telephone expenses are projected at $\$ 200$ per month per representative and $\$ 250$ per month for the field managers.

Preparation and distribution of information bulletins and other communications from the home office to each sales representative are estimated at $\$ 18$ per month per representative.

Costs to send urgent overnight documents to representatives are estimated at $\$ 9$ per package. It is estimated that 10 such shipments will be necessary to each representative per year. 


\section{Non-recurring Costs}

Detail bags will be purchased at a cost of $\$ 100$ per representative.

The printing costs for business cards for each sales representative and field manager are estimated at $\$ 25$ per representative.

\section{Storage Costs}

Each sales representative will require a storage unit for samples. Projected cost for each unit is $\$ 90$ per month.

\section{QUESTIONS}

1. Prepare a program budget based upon the information provided above. Format the budget to include each of the ten categories with sub-totals for each category. Label each line item clearly. Show supporting computations on a separate schedule.

2. Using an outside vendor to provide services can be beneficial. At the same time certain benefits are lost. Identify the: a) advantages and, b) disadvantages of outsourcing the sales function.

3. Once the strategic decision to outsource part of the sales function is made, the selection process can begin. Identify the most important factors to consider when selecting a "vendor." (i.e. a CSO)

4. Identify the most important factors for successful outsourcing.

5. Define typical outsourcing strategies. Consider business, financial and technical strategies.

6. Product managers are responsible for most every facet of a product's success. List the typical responsibilities and duties of a product manager of a patent-protected drug.

7. Discuss the impact of e-commerce on the pharmaceutical industry. Specifically, how will customer service and price be affected?

8. A balanced scorecard is a means of measuring an organization's success. It consists of an integrated set of performance measures that are derived from the company's strategy (as measured in terms of goals) and that support the company's strategy throughout the organization. Prepare a balanced scorecard for HDI. Your answer should identify core financial, customer, and learning and growth goals. It is not necessary to quantify each metric for each goal. Rather, you are to identify the desired change (increase or decrease) for each goal.

\section{AUTHOR INFORMATION}

Dr. Joseph M. Larkin is an Associate Professor of Accounting in the Haub School of Business at Saint Joseph's University. He joined the faculty in 1984. He earned his undergraduate degree from Saint Joseph's University and holds graduate degrees from The Pennsylvania State University and Temple University. He has published in the Journal of Business Case Studies, Journal of Business Ethics, Advances in Managerial Accounting, Journal of Applied Business Research among others. 